\title{
AN EVALUATION OF NON-SURVEY ESTIMATION TECHNIQUES FOR REGIONAL INPUT-OUTPUT MODELS
}

\author{
Sharon M. Brucker and Steven E. Hastings*
}

\section{Introduction}

The need for an acceptable non-survey method of estimating regional input-output (IO) models is well known. Many methods have been proposed and evaluated. Evaluations of methods have been presented by Czamanski and Malizia (1969), Shaffer and Chu (1969), Shaffer (1969), Morrison and Smith (1974), McMenamin and Haring (1974), and more recently, Cartwright, et al. (1981) and Stevens, et al. (1981). All have involved the comparison of non-survey coefficients to survey coefficients. The earlier non-survey tables were estimated from highly aggregated national tables.

This paper compares the coefficients in a survey-based input-output model to coefficients determined by regionalizing the 1972 United States input-output table at its most disaggregated level (496 sectors). The use of such disaggregated data has been proposed by most evaluators of non-survey methods to reduce the burden of the assumption that product mix does not vary between the nation and the region. ${ }^{1}$

The objective of this study is twofold: to evaluate the relative merits of several modifications to non-survey methods and to explore the benefits of using a more disaggregated national table. The paper is organized in four parts: 1) a description of the non-survey methodologies to be evaluated, 2) a comparison of I-O tables and multipliers estimated by the non-survey methods to the survey I-O tables and multipliers, 3) a comparison of multipliers produced from disaggregated and aggregated national tables, and finally, 4) conclusions regarding the value of various non-survey methods and benefits of using a disaggregated national table.

The focus of the study is to determine which of four non-survey methods of estimating a regional I-O table provides the most accurate

\footnotetext{
*University of Delaware. Published with the approval of the Director of the Delaware Agricultural Experiment Station as Miscellaneous Paper No. 1034 by the Department of Agricultural and Food Economics, College of Agricultural Sciences, University of Delaware, Newark, DE 19711. The authors wish to thank William Latham and anonymous referees for helpful comments.
}

representation of the structure existing in a region. The region of analysis is Sussex County, Delaware, a rural county in the southern part of the state. An I-O table originally consisting of 42 sectors was estimated for this region using survey data collected for the year 1972 (Brucker and Cole, 1979). Acknowledging Jensen's (1978) warnings against such an assumption, for purposes of this paper, the survey table is assumed to accurately depict the Sussex County economy. The coefficients obtained by several non-survey methods will be compared to the survey coefficients. Variables to be compared include coefficients from the direct requirements tables, output multipliers, income multipliers and imports.

\section{Non-Survey Methods of Estimating I-O Models}

Many non-survey methodologies have proliferated in the past two decades (Stone, 1970, Lecomber, 1971 and McMenamin and Haring, 1974). Some are short-cut methods to determine multipliers only like those designed by Drake (1976) and Burford-Katz (1981). Some were incorporated in extensive modeling systems such as RIMS II by Cartwright et al (1981) and the Stevens model for transportation impact analysis (1981). Many include modifications of older methods such as location quotient and supply-demand pool. Some of the newer methods have already been extensively evaluated in other studies (Burford and Katz, 1981, Cartwright, Bumiller and Gustily, 1981, Drake, 1976, Malizia and Bond, 1974 and McMenamin and Haring, 1974).

Therefore, in this section, four non-survey methods of estimating regional input-output models are chosen and described. These are: location quotients, based on output and employment, supply-demand pool, and a method of estimating only multipliers proposed by Burford and Katz (1981).

All of the methods except Burford-Katz will be used to estimate a full Input-Output table both open and closed with respect to house- 
holds. The Leontief-inverse method will be used to determine multipliers.

\section{Location Quotients}

The most frequently used non-survey method has been the location quotient method, where a location quotient is defined as:

$$
\mathrm{LQ}_{\mathrm{i}}=\frac{\mathrm{x}_{\mathrm{i}} / \mathrm{x}}{\mathrm{X}_{\mathrm{i}} / \mathrm{X}}
$$

The location quotient for an industry $i$ in a region is the ratio of the regional output of industry $i\left(x_{i}\right)$ to total regional output $(x)$ divided by the ratio of national output of industry $\mathrm{i}\left(\mathrm{X}_{\mathrm{i}}\right)$ to total national output $(\mathrm{X})$. Direct requirements from the national I-O table $\left(a_{i j}\right.$ 's can be regionalized by multiplying the direct requirement $a_{i j}$ of a given industry, $j$, by the location quotient $\left(\mathrm{LQ}_{\mathrm{i}}\right)$ for the supplying industry, i.

Because users of the location quotient technique do not always have total output figures for each industrial sector, employment figures are often used to estimate location quotients. To evaluate the practice of using location quotients based on employment rather than total output, both were calculated for the sectors in Sussex County. These location quotients will be referred to as LQP and LQE for productionbased and employment-based location quotients, respectively.

\section{Supply Demand Pool Method}

Another non-survey estimation method used in this paper, referred to as POOL, follows closely the technique used by Boisvert and Bills (1976). The technique is a modified supplydemand pool technique where the 496 sector national direct requirements table is collapsed to 29 sectors comparable to the survey using weights based on county employment in each of 496 sectors. ${ }^{2}$ County employment data for fourdigit SIC industries was available from the Delaware Department of Labor. ${ }^{3}$

The weighting procedure involves two steps. The first step is to aggregate the columns. This step weights each disaggregated coefficient $\left(a_{k p}\right)$ of the national table $\left(A_{k p}\right)$ according to the economic importance of the disaggregated sector in the region. The weight is the ratio of the regional employment in the disaggregated sector $(p)$ to the total regional employment in the newly aggregated sector (j), determined by summing disaggregated sector employment according to the specific sample definition. The weight is:

$$
\frac{E_{p}}{\sum_{p=1} E_{p}}
$$

where $E_{p}$ is regional employment in industry $p$ and the disaggregated sectors 1 through $\iota$ make up the aggregated sector $\mathrm{j}$. This procedure produces coefficients for the aggregated sectors $\left(a_{k j}\right.$ 's) that reflect the region's product mix. Technically, this is accomplished by:

$a_{k j}=\sum_{p=1} a_{k p}\left(\frac{E_{p}}{\sum \iota_{p=1} E_{p}}\right)$

where:

$$
\begin{aligned}
\mathrm{k}= & \text { rows in national table, } 1 \ldots \mathrm{n} . \\
\mathrm{p}= & \text { columns in the national table, } 1 \ldots \mathrm{n} . \\
\mathrm{j}= & \text { columns in regional table, } 1 \ldots \mathrm{m}, \\
& \mathrm{m}<\mathrm{n} . \\
\mathrm{I}= & \text { rows in regional table, } 1 \ldots \mathrm{m} .
\end{aligned}
$$

In the second step, the rows are aggregated to correspond to the new sectors. This produces a matrix of regional technical coefficients $\left(a_{i j}\right.$ 's). In this step, coefficients for any sector with no employment in the region are not added into the new regional production coefficients, but rather are defined as imports (non-competing). This reduces many of the problems of estimating imports.

To account for competing imports, (those for which there is some production in the region), the supply-demand pool procedure is used to adjust the $a_{i j}$ 's. Each production coefficient is divided into a regional purchase component and an import component.

Regional transactions are estimated by multiplying regional gross industry output totals by the regional direct requirement table. Then, final demand is estimated and the region's share of national final demand. ${ }^{4}$ At this point, dollar purchases have been estimated for each cell in the table. Summing the elements in each row (i) gives total estimated regional demand $\left(r_{i}\right)$ for sector $i$. Having modified the procedure used by Boisvert and Bills,

$$
\begin{gathered}
r_{i}=\sum_{j=1}^{m} a_{i j} x_{j}+\sum_{f_{=1}} C_{i j} \\
\bar{y} \\
\bar{Y}
\end{gathered}
$$

The difference between total estimated demand for a sector's output $\left(\mathbf{r}_{\mathrm{i}}\right)$ and the total supply $\left(x_{i}\right)$ of that sector's output can be defined 
as the sector balance $\left(b_{i}\right)$ where $b_{i}=x_{i}-r_{i}$. If $b_{i}$ is greater than 0 , then the balance is allocated to exports. If, however, $b_{i}$ is less than 0 then the regional transactions and thus regional direct requirements for that sector's output will be adjusted downward. This procedure reflects the assumptions that all local demand is met first from local supply and that any importing is done proportionately on the basis of the relative purchases from the sector to total demand from the sector. The adjusted coefficients $\left(\mathrm{a}_{\mathrm{ij}}\right)$ are

$$
a_{i j}^{r y}=a_{i j} x_{i} k / r_{i}
$$

and competing imports for each unit of output of sector $\mathrm{j}\left(\mathbf{M}_{\mathrm{j}}\right)$ are

$$
\mathbf{M}_{\mathrm{j}}=\sum_{\mathrm{i}=1}^{\mathrm{m}}\left(\mathbf{a}_{\mathrm{ij}}-\mathbf{a}_{\mathrm{ij}}^{\hat{i}}\right)
$$

This final adjustment produces regional transactions and direct requirements tables that reflect regional production.

\section{Burford-Katz}

If there is no need for a complete regional I-O table, Burford and Katz (1981), have provided a straightforward method for estimating multipliers $(\mu)$ only. This method has been included in the evaluation because of its appealing ease of calculations; however, it should be kept in mind that although the B-K method requires only that the fraction of an industry's purchases made in the region be known, this data is usually not available. ${ }^{5}$ The fraction of total output, known as total intermediate input, is called $\mathrm{w}_{\mathrm{j}}$. The Burford-Katz method provides estimates of the multiplier for a sector, $\mu_{j}$, based on the intermediate input of sector $j, w_{j}$, relative to the mean intermediate purchase of all sectors, $\overline{\mathbf{w}}$. Their equation is:

$$
\mu_{j}=1+w_{j} /(1-\bar{w})
$$

This equation reflects the fact that sector multipliers will be above average for sectors having greater than average intermediate inputs. This equation was used to estimate the multipliers for Sussex County.

\section{Comparison of I-O Coefficients}

To evaluate the accuracy of the estimates made by the LQE, LQP, and POOL non-survey methods, the coefficients and multipliers are compared to the coefficients and multipliers of the survey-based table.

\section{Measures of Closeness}

Morrison and Smith (1974) provide an excellent discussion of various statistics which could be used to evaluate how close non-survey coefficients or multipliers are to the survey coefficients and multipliers. Some alternatives include chi-square, simple regression coefficients, correlation coefficients, simple error or difference, mean absolute difference, and mean proportional difference. Of these, four are used in this study: correlation, regression, chisquare and mean proportional diffrence.

The advantage of chi-square, regression and correlation is that each provides a test for statistical significance. However, statisticians indicate that the limits on the values of the I-O coefficients make the accuracy of such tests of statistical significance doubtful because the initial assumptions of randomness are not met. The primary method of comparison used in this study is mean proportional difference. So that the results of this study might be compared to earlier evaluations which used chi-square, correlation and regression measures, they are also included in the results.

\section{Mean Proportional Differences}

To compare the closeness of the three nonsurvey tables to the survey table for several variables, it would be most helpful to look at one measure of closeness for several variables. The measure chosen for this comparison is the mean proportional difference (also called mean absolute percentage error, MAPE).

It is the most often used and clearly understood measure. It is defined as:

$$
\frac{\delta=\sum_{\mathrm{i}=1}^{\mathrm{m}} \frac{\left|\left(\mathrm{a}_{\mathrm{ij}}-\mathrm{a}_{\mathrm{ij}}{ }^{*}\right)\right|}{\mathrm{a}_{\mathrm{ij}}}}{\mathrm{m}}
$$

where:

$\mathrm{a}_{\mathrm{ij}}$ are survey values and

$\mathrm{a}_{\mathrm{ij}} *$ are non-survey values.

The sum of absolute differences provides a measure of distance of two columns of tables. If each difference is calculated as a proportion, overemphasis on large coefficients is avoided. When divided by the number of coefficients or multipliers, the mean proportional difference reflects the average proportional (or percentage, if multiplied by 100) difference of the non-survey value from the survey value.

\section{Overall Comparison}

Table 1 shows the mean proportional difference of LQE, LEP and POOL generated tables. 
TABLE 1

Mean Proportional Differences.

\begin{tabular}{|c|c|c|c|}
\hline Variable & LQE & LQP & POOL \\
\hline All production coefficients & 6.26 & 3.30 & 3.32 \\
\hline $\begin{array}{l}\text { Column sums (percent } \\
\text { regional purchases) }\end{array}$ & 2.24 & 2.10 & 1.94 \\
\hline $\begin{array}{l}\text { All production coefficients } \\
\text { with households }\end{array}$ & 6.31 & 3.34 & 3.35 \\
\hline Type I Output Multipliers & .1691 & .1517 & .1222 \\
\hline Type II Output Multipliers & .4674 & .2172 & .1701 \\
\hline Income Multipliers & .3950 & .2220 & .1819 \\
\hline Imports $^{a}$ & .8987 & .7886 & .9129 \\
\hline $\begin{array}{l}\text { Imports (without } 3 \text { prob- } \\
\text { lem sectors) }\end{array}$ & .4224 & .4035 & .3778 \\
\hline
\end{tabular}

"Appendix A, Table 3.

As can be seen, the POOL method of estimating the Sussex County I-O table gives coefficients and multipliers which are on average closer to the survey table in every case, except when comparing the two entire direct requirements tables (all production coefficients). In this case, the POOL method and the LQP method produce equally close tables.

For Type I output multipliers, the POOL method estimated multipliers with a mean proportional difference $(\delta)$ of .12 while the $L Q E$ and LQP were .16 and .15 respectively. For Type II output multipliers, the range was even greater with the POOL again having the lowest mean proportional difference of .17 while LQE have .48 and .22 , respectively. For the income multipliers the mean proportional differences were again lowest for the POOL and highest for $\mathrm{LQE}$. It is valid to point out that our POOL technique's estimates of type I and II output and income multipliers (which are on the average, 12,17 , and 18 percent different, respectively, from the survey based table) may not be accurate enough for many purposes. It is still a higher degree of closeness than that associated with the LQE and LQP methods.

It is interesting to note that there is a fairly substantial difference between the mean proportional differences associated with using location quotients based on employment and those based on production. In every case, the coefficients and multipliers derived from the production-based location quotients are closer to the survey values than those based on employment figures. The income multipliers estimated from the LQE method are seen to be more than 39 percent different from the survey- based table, while those estimated from the LQP method are about 22 percent different. With Type II output multipliers, the gap between the LQE and LQP methods is even more striking. In this case, the LQE estimated multipliers are almost 47 percent larger than the survey-based ones, while those estimated from the LQP method are only 22 percent higher.

\section{Multipliers}

A sector-by-sector comparison of estimated multipliers can be instructive. The Type I multipliers estimated by the survey and all four non-survey methods, as well as the proportional differences, are presented in Table 2.

The mean proportional differences over all sectors ranged from .0096 to .1691 for the various non-survey methods. The B-K method yielded multipliers with the smallest proportional difference for almost every industry, most being less than 1 percent different than the survey and the largest difference of a B-K multiplier being 3 percent in the livestock sector. Obviously, the mean proportional difference over all industrial multipliers is by far the lowest for B-K, 0.96 percent. This is in keeping with Burford and Katz's own observations that the percent error will be smaller as $\overline{\mathrm{w}}$ is smaller. Since $\overline{\mathbf{w}}$ of 0.17 is very low, the closeness of the multiplier estimates to those from the survey is as expected. However, since many non-survey models may not have the data to use the B-K method, it may be instructive to compare the relative merits of the other methods.

The POOL technique multipliers had proportional differences ranging from .003 to .4408 , but there were only 5 sectors where the difference was greater than 20 percent and there were 15 sectors where the difference was less than 10 percent. The LQP technique yielded similar distribution of proportional differences. The range of proportional differences for the LQP was from .7411 to .0056, where the percentage difference in 7 sectors was greater than 20 percent and in 15 sectors less than 10 percent. The LQE multipliers had proportional differences ranging from .8129 to .0017 , with 9 sectors' multipliers over 20 percent different from the survey multipliers and 14 sectors less than 10 percent.

It is not encouraging to note that for all three non-survey methods the largest two discrepancies from the survey occur in the largest indus- 
TABLE 2

Comparison of Output Multipliersa Estimated by Non-Survey Methods to Survey-Based Multipliers.

\begin{tabular}{|c|c|c|c|c|c|c|c|c|c|}
\hline \multirow[t]{2}{*}{ Sector } & \multicolumn{5}{|c|}{ Multipliers } & \multicolumn{4}{|c|}{ Proportional Differences } \\
\hline & Survey & LQE & LQP & Pool & B-K & LQE & LQP & Pool & B-K \\
\hline 1 F.Crops & 1.549 & 1.322 & 1.207 & 1.205 & 0.504 & -.1466 & -.2208 & -.2221 & $-.0290^{*}$ \\
\hline 2 Frt. Veg. & 1.397 & 1.285 & 1.212 & 1.161 & 0.380 & -.0802 & -.1324 & -.1689 & $-.0124^{*}$ \\
\hline 3 Livestock & 1.487 & 1.745 & 1.663 & 1.745 & 0.442 & .1735 & .1184 & .1735 & $-.0305^{*}$ \\
\hline 4 Broilers & 1.266 & 2.113 & 2.014 & 1.356 & 0.230 & .6690 & .5908 & .0711 & $-.0287^{*}$ \\
\hline 5 Vet. & 1.068 & 1.259 & 1.197 & 1.201 & 0.068 & .1788 & .1208 & .1245 & $.0005^{*}$ \\
\hline 6 Ag Supply & 1.132 & 1.545 & 1.46 & 1.303 & 0.135 & .3648 & .2898 & .1511 & $.0031^{*}$ \\
\hline 7 P. Proc. & 1.352 & 2.451 & 2.354 & 1.948 & 0.339 & .8129 & .7411 & .4408 & $-.0095^{*}$ \\
\hline 8 V. Proc. & 1.208 & 1.418 & 1.328 & 1.345 & 0.190 & .1738 & .0993 & .1134 & $-.0147 *$ \\
\hline 9 Fishfsim & 1.114 & 1.191 & 1.143 & 1.132 & 0.122 & .0691 & .0260 & .0162 & $.0070^{*}$ \\
\hline 10 Cons. New & 1.219 & 1.215 & 1.173 & 1.178 & 0.213 & $-.0033^{*}$ & -.0377 & -.0336 & -.0051 \\
\hline 11 Cons. Mnt. & 1.171 & 1.239 & 1.206 & 1.214 & 0.138 & .0581 & .0299 & .0367 & $-.0278 *$ \\
\hline 12 Apparel & 1.012 & 1.317 & 1.273 & 1.28 & 0.013 & .3014 & .2579 & .2648 & $.0006^{*}$ \\
\hline 13 Oth. Man. & 1.018 & 1.415 & 1.359 & 1.372 & 0.019 & .3900 & .3350 & .3477 & $.0014 *$ \\
\hline 14 Trans & 1.143 & 1.223 & 1.167 & 1.207 & 0.150 & .0700 & .0210 & .0560 & $.0064 *$ \\
\hline 15 Commun. & 1.051 & 1.3 & 1.289 & 1.275 & 0.053 & .2369 & .2265 & .2131 & $.0023^{*}$ \\
\hline 16 Utility & 1.145 & 1.41 & 1.295 & 1.392 & 0.152 & .2314 & .1310 & .2157 & $.0060 *$ \\
\hline 17 Whlsl Td. & 1.256 & 1.192 & 1.15 & 1.161 & 0.268 & -.0510 & -.0844 & -.0756 & $.0097 *$ \\
\hline 18 Restaurant & 1.258 & 1.341 & 1.251 & 1.246 & 0.261 & .0660 & -.0056 & -.0095 & $.0026 *$ \\
\hline 19 Ret. Trade & 1.199 & 1.189 & 1.118 & 1.131 & 0.206 & -.0083 & -.0676 & -.0567 & $.0058^{*}$ \\
\hline 20 Finance & 1.196 & 1.231 & 1.187 & 1.201 & 0.202 & .0293 & -.0075 & $.0042^{*}$ & .0050 \\
\hline 21 Insurance & 1.096 & 1.33 & 1.289 & 1.23 & 0.098 & .2135 & .1761 & .1233 & $.0019^{*}$ \\
\hline 22 Real Estate & 1.352 & 1.217 & 1.142 & 1.145 & 0.377 & -.0999 & -.1553 & -.1531 & $.0182^{*}$ \\
\hline 23 Lodging & 1.353 & 1.392 & 1.223 & 1.243 & 0.366 & .0288 & -.0961 & -.0813 & $.0093^{*}$ \\
\hline 24 Pers. Ser. & 1.242 & 1.239 & 1.146 & 1.152 & 0.253 & $-.0024^{*}$ & -.0773 & -.0725 & .0091 \\
\hline 25 Repair & 1.159 & 1.161 & 1.103 & 1.107 & 0.172 & $.0017 *$ & -.0483 & -.0449 & .0114 \\
\hline 26 Amusement & 1.111 & 1.37 & 1.312 & 1.293 & 0.118 & .2331 & .1809 & .1638 & $.0067 *$ \\
\hline 27 Profess. & 1.087 & 1.194 & 1.158 & 1.162 & 0.091 & .0984 & .065 & .0690 & $.0042 *$ \\
\hline 28 Other Ser. & 1.262 & 1.278 & 1.206 & 1.212 & 0.259 & .0127 & -.0444 & .0396 & $-.0023^{*}$ \\
\hline 29 Education & 1.167 & 1.282 & 1.152 & 1.163 & 0.174 & .0985 & -.0129 & .0034 & $.0062 *$ \\
\hline Mean $^{b}$ & 1.209 & 1.375 & 1.303 & 1.268 & 1.2067 & .1691 & .1517 & .1223 & .0096 \\
\hline
\end{tabular}

* Indicates lowest proportional difference for each sector.

a Without endogenous households.

b Mean of absolute values.

try in Sussex County-broiler production and processing. ${ }^{6}$ The smaller discrepancies seem to occur in the service industries, trade, finance and construction. ${ }^{7}$ The relative errors seem to be consistent whichever method you use, suggesting that some sectors may need to be surveyed whatever non-survey method is chosen. This consistency is encouraging in that a semisurvey of only dominant regional industries should greatly improve any non-survey results.

\section{Imports}

Table 1 contains a comparison of imports using the mean proportional difference. This clearly indicates that the estimate of regional purchases is still an error-producing step in all of the non-survey procedures. It is only slightly more heartening that if the overestimates and underestimates of the various sectors (which can be seen in Table 3, Appendix A) are allowed to net each other out, the estimates of total imports relative to the survey total imports are greatly improved. Specifically, the LQE estimate of $\$ 246,958,180$ is 32 percent less than the survey total imports of $\$ 363,860,100$, the LQP estimate of $\$ 212,493,870$ is 41.6 percent les than the survey, and the POOL estimate of $\$ 393,291,680$ is only 8 percent greater than the survey.

It would be instructive to look at where the divergence from the survey takes place. The major errors in the estimating of imports are in the same three sectors for all three non-survey methods. The magnitude of these errors ranges from 200 to 700 percent and, therefore, they are strongly impacting the mean proportional difference. The three sectors are 6, 9, and 20, which are Agricultural Supply, Fishing, Forestry and Mining, and Finance, respectively. In the two first sectors, Agricultural Supply and 
TABLE 3

Regression Analysis Comparing Non-Survey to Survey Tables.

\begin{tabular}{|c|c|c|c|}
\hline Variable & LQE & LQP & POOL \\
\hline \multicolumn{4}{|l|}{ All Production Coefficients $(\mathrm{N}=841)$} \\
\hline $\begin{array}{l}\text { Mean (Survey }=.0059) \\
\text { Regression constant }\left(\alpha_{\mathrm{j}}\right) \\
\text { Regression coefficient }\left(\beta_{\mathrm{j}}\right) \\
\text { Coefficient of determination }\left(\mathrm{R}^{2}\right)\end{array}$ & $\begin{array}{l}.0092 \\
.0033 \\
.2872 \\
.2997\end{array}$ & $\begin{array}{l}.0076 \\
.0037 \\
.2959 \\
.2945\end{array}$ & $\begin{array}{l}.0071 \\
.0034 \\
.3614 \\
.3352\end{array}$ \\
\hline \multicolumn{4}{|l|}{$\begin{array}{l}\text { All Production Coefficients } \\
\text { With Households }(\mathrm{N}=900)\end{array}$} \\
\hline $\begin{array}{l}\text { Mean (Survey }=.0193) \\
\text { Regression constant }\left(\alpha_{j}\right) \\
\text { Regression coefficient }\left(\beta_{j}\right) \\
\text { Coefficient of determination }\left(R^{2}\right)\end{array}$ & $\begin{array}{l}.0250 \\
.0003 \\
.7599 \\
.8189\end{array}$ & $\begin{array}{l}.0233 \\
.0014 \\
.7645 \\
.8246\end{array}$ & $\begin{array}{c}.0183 \\
.0002 \\
1.0372^{*} \\
.8008\end{array}$ \\
\hline $\begin{array}{l}\text { All Interdependence Coefficients }(N=841) \\
\text { Mean (Survey }=.0417) \\
\text { Regression constant }\left(\alpha_{j}\right) \\
\text { Regression coefficient }\left(\beta_{\mathrm{j}}\right) \\
\text { Coefficient of determination }\left(R^{2}\right)\end{array}$ & $\begin{array}{r}.0474 \\
-.0028 \\
.9388 \\
.9693\end{array}$ & $\begin{array}{r}.0449 \\
-.0006 \\
.9426 \\
.9714\end{array}$ & $\begin{array}{l}.0438 \\
.0002 \\
.9469 \\
.9818\end{array}$ \\
\hline \multicolumn{4}{|l|}{$\begin{array}{l}\text { All Interdependence Coefficients } \\
\text { with Households }(\mathrm{N}=900)\end{array}$} \\
\hline $\begin{array}{l}\text { Mean (Survey }=.0796) \\
\text { Regression constant }\left(\alpha_{\mathrm{j}}\right) \\
\text { Regression coefficient }\left(\beta_{\mathrm{j}}\right) \\
\text { Coefficient of determinatoin }\left(\mathbf{R}^{2}\right)\end{array}$ & $\begin{array}{r}.1128 \\
-.0081 \\
.7773 \\
.3985\end{array}$ & $\begin{array}{r}.0890 \\
-.0015 \\
.9108 \\
.9429\end{array}$ & $\begin{array}{c}.0713 \\
-.0056 \\
1.0381^{*} \\
.9288\end{array}$ \\
\hline
\end{tabular}

The null hypothesis that $\beta_{\mathrm{j}}$ is equal to zero was rejected at the .001 level for all of the above equations.

*The null hypothesis that $\beta_{\mathrm{j}}$ is equal to one was not rejected at the .001 level.

Fishing, Forestry and Mining, there are obvious differences in product mix not captured by the weighting procedure. In the Finance sector, the sampling in the survey could be questioned and therefore, the accuracy of the sample could be at fault. If the three problem sectors are eliminated, then the mean proportional differences would be: $.4224, .4035$ and .3778 for the LQE, LQP and POOL methods, respectively.

\section{Regression and Correlation Analysis}

In order to test the general relationship between the survey and non-survey values, regression and correlation analysis were used. The correlation analysis related survey values to non-survey values. The regression analysis estimated the following relationship:

$$
a_{i j}=\alpha_{j}+\beta_{j} a_{i j}^{*}
$$

where:

$a_{i j}$ is a survey coefficient, the dependent variable.

$a_{i j}^{*}$ is a non-survey coefficient, independent variable.

If the non-survey estimates are close to the sur- vey, then the $\alpha_{j}$, term will be expected to tend toward zero and the $\beta_{\mathrm{j}}$ term toward 1 .

In Table 3, the results of the regression analysis are given for all production coefficients (from the direct requirements tables), where all 841 cells of the non-survey direct requirements table were regressed on those of the survey table. Results for a closed model, including households and for the interdependence tables as a whole, are also reported in Table 3.

In general, the non-survey values are related to the corresponding survey value. The significance of the regression coefficients $\left(\beta_{j}\right)$ indicate a significant overall relationship between the non-survey and survey values in all four tables for all three methods. The POOL method seems to most closely estimate the survey tables as indicated by regression coefficients close to 1 . In those cases where the regression coefficient is less than one it is indicative that the non-survey tables have over-estimated the coefficients. As can be seen by the relative mean values for the coefficients, the LQE consistently gives the greatest over-estimation.

Non-survey coefficients were correlated with survey coefficients by column for both the direct requirements table and the inverted, interde- 
pendence table. It is interesting to note the difference in results. For direct requirements, all three methods consistently estimated some sectors well (correlation coefficients significant at the .05 and .001 level). However, there are many sectors for which no method provides a column of production coefficients highly correlated with the survey's column. This could, in part, be due to the many zero elements in the survey input structure.

The correlation of the interdependence coefficients produced correlation coefficients that were significant at the .001 level for every sector. In all but one sector, the correlation coefficients were .9900 or greater. The one exception was the poultry processing sector where the coefficients were $.90, .91$, and .95 for the LQE, LQP, and POOL methods, respectively.

\section{Chi-square Analysis}

Because of serious objections to the use of the chi-square test discussed in detail by Morrison and Smith (1974), it will be used in this paper only as a relative measure and for reference to Shaeffer and Chu's (1969) results.

The Chi-square statistic is:

$\mathrm{X}_{\mathrm{j}}^{2}=\sum_{\mathrm{i}=1}^{\mathrm{m}} \quad \frac{\left(\mathrm{a}_{\mathrm{ij}}-\mathrm{a}_{\mathrm{ij}}{ }^{*}\right)^{2}}{\mathrm{a}_{\mathrm{ij}}}$

where $a_{i j}$ 's are used in percentage form so that standard table criterion values will apply.

Table 4 in Appendix A shows the sectors for which there was no reason to reject the null hypothesis that the non-survey estimates of the production coefficients were the same as the survey-based coefficients. Using the chi-square test as a relative measure of goodness of fit, the table also indicates which non-survey method had the lowest chi-square value in 18 of the 29 sectors. Also, in most cases when one method provided an acceptable chi-square value so did the others, but in the case of the broiler indus-
try-Sussex County's largest industry, sectors 4 and $7-$ only the POOL method yielded chisquare results below the criterion value.

\section{Using Aggregated Versus Disaggregated National Tables}

One of the objectives of this study is to compare the accuracy of the location quotient method of estimating I-O coefficients when an aggregated and a disaggregated national table are regionalized.

The analysis up to this point has been based on collapsing a 496 sector national I-O table to a 29 sector table. A second set of location quotient estimates of Sussex County I-O tables were made using the 1972 national I-O table with 77 sectors (Appendix A, Table 2). For these estimates, the 77 sector table is aggregated by row and column. Due to the level of aggregation and survey sector definition, this results in 21 sectors comparable to the survey. The survey transactions table is also aggregated into the same 21 sectors. Employment and productionbased location quotients are then calculated for the 21 sectors and multipliers estimated. Survey multipliers for the corresponding sectors are also calculated. These location quotientestimated tables of coefficients and multipliers can be compared to those from the survey. Table 4 facilitates such a comparison for the output multipliers only. Because we are also interested in evaluating the Burford-Katz method for estimating multipliers, the closeness of those multipliers to the survey multipliers is also evaluated.

Table 4 summarizes the comparison of survey and non-survey based output multipliers for all techniques, including location quotient methods where both an aggregated and disaggregated national table were used. The estimating techniques for the aggregated table will be

TABLE 4

Type I Output Multipliers

\begin{tabular}{|c|c|c|c|c|c|c|c|c|}
\hline Measure & $\begin{array}{c}\text { Survey } \\
29 \\
\text { Sectors }\end{array}$ & LQE & LQP & POOL & B-K & $\begin{array}{c}\text { Survey } \\
21 \\
\text { Sectors }\end{array}$ & LQEAG & LQPAG \\
\hline $\begin{array}{l}\text { Mean of Multipliers } \\
\text { Mean Proportional }\end{array}$ & 1.209 & 1.375 & 1.303 & 1.268 & 1.207 & 1.182 & 1.509 & 1.503 \\
\hline Diffrence & & 0.1691 & 0.1517 & 0.1223 & 0.0096 & & 0.2905 & 0.2926 \\
\hline Sum of Absolute & & & & & & & & \\
\hline Difference & & 5.904 & 5.385 & 4.308 & 0.359 & & 6.8668 & 6.7366 \\
\hline Mean Difference & & 0.2036 & 0.1857 & 0.1486 & 0.0124 & & 0.3270 & 0.3276 \\
\hline
\end{tabular}


referred to as LQEAG and LQPAG. Overall, the results indicate that better non-survey estimates of Type I multipliers are achieved when a disaggregated table is regionalized.

It is not surprising to note the striking difference in the mean proportional differences of the LQE and LQP and that of the LQEAG and LQPAG. The mean differences for the LQE and LQP are 17 and 15 percent, respectively; while the mean proportional differences for the LQEAG and LQPAG are both 29 percent. Since input-output researchers have been proposing the use of a more disaggregated national table as a means to improve non-survey results, these mean proportional differences and the other measures of closeness in Table 4 only confirm their expectations. ${ }^{8}$

Observations concerning the difference in the multipliers estimated using the employmentbased and production-based location quotients may be more unexpected. The differences are quite pronounced when comparing type II output multipliers and income multipliers. The difference is less acute when comparing Type I output multipliers and almost non-existent when comparing the output multipliers estimated from the aggregated national table. Hence, it may be acceptable to use the employment-based location quotient as a proxy for the production-based location quotient when using the aggregated national table or when only estimating Type I output multipliers.

On the basis of the data in Table 4, it can be seen again that the multipliers estimated using the B-K method are closer to the survey-based multipliers. As Morrison and Smith found with RAS earlier, this indicates that if data for the percent of total industry expenditures that are regional are available, then estimates of multipliers will be very accurate. The B-K method is appealing in its straightforward calculation and accuracy. However, since its data requirements are rarely fulfilled by non-survey data, it may still be necessary to use one of the other methods.

\section{Conclusions}

While the authors recognize the limitations of results based on a study on one small county and its specific economic structure, there are several conclusions that seem clear from this study. First, if one needs to estimate a full I-O table and cannot undertake a survey, the POOL method based on the most disaggregated national table will provide estimated coefficients and multipliers closer to a survey than would location quotient methods. This is a finding not shared by earlier investigations. A possible reason for this is the different method used to estimate final demand. If only the multipliers are needed and data on regional purchases as a percent of total expenditures is available, then the Burford-Katz method would minimize expense and provide very accurate estimates of output multipliers. In fact, the results may indicate that a survey to determine that total regional purchases as a percent of total expenditure would be very cost effective.

As expected, use of a disaggregated national table does provide regional output multipliers that are closer to survey estimated multipliers. The use of employment-based location quotients as a proxy for production-based location quotients seems to be justified if one is using an aggregated national table. However, the two will not be interchangeable if one is using a disaggregated national table.

Since the estimation of imports by sector seems to be very inaccurate, confirming the work of both Burford and Katz (1981), and Stevens and Trainer (1976), it would seem wise to try more semi-survey techniques. It appears that non-survey methods are especially vulnerable in the very sectors for which they are most important-the large industries in a region. Possibly this would indicate the need for, at the very least, a survey of the percent of total expenditures made on local purchases for the largest regional industries.

\section{FOOTNOTES}

${ }^{1}$ Schaffer and Chu (1969) mention this on p. 96 and Morrison and Smith (1974) made reference to this in the conclusions section of their book.

2This weighting method was first used by Shen in 1960 . The POOL technique is similar to that in Moore and Peterson's Utah study (1955).

${ }^{3}$ Collected for Unemployment Insurance Service and therefore, probably available in all states. This is actually a proxy for output data which is not available at the fourdigit SIC level.

4Following Isard's (1953) method for determining regional commodity balances, the determination of regional final demand from national final demand dollar figures was estimated by multiplying national final demand by the ratio of regional personal income $(y)$ to national personal income (Y). Ratios of other relevant measures such as regional to national expenditures were used to estimate the education column and new constructions figures for the capital formation column.

${ }^{5}$ Both Morrison and Smith (1974) and Czamanski and Malizia (1969) evaluations have included Stone's (1970) 
non-survey technique, RAS. They found its tables considerably closer to a survey-based table than LQ methods. Because it requires the same information as the B-K method, but is more difficult to perform, it is not included in this study.

'Czamanski and Malizia also found that region's specialized industries are often misestimated.

7This is the opposite of what Czamanski and Malizia found-that tertiary industries exhibit the largest errors.

${ }^{8}$ It may be significant to note that not only do all our measures of closeness indicate the increased accuracy associated with using the disaggregated national table, but also comparisons with results of earlier studies confirm this. Although there are many problems with comparing results across different regional models, it is interesting that the mean proportional differences for output multipliers for LQE, LQP and POOL for Sussex county, all based on the 496 sector national I-O model, are all lower than the mean proportional differences in the Morrison and Smith evaluation (from .1724 to .2525 , except for the mean proportional difference of the RAS estimated table, -.0006 , from the survey based table). Using the chi-square test (with $\alpha=$ .05 ), the hypothesis of sameness can not be rejected for a large percent of sectors in the Sussex non-survey studies (18 of 29) than in Schaffer and Chu's results (7 of 23).

\section{REFERENCES}

1. Bacharach, M. Biproportional Matrices and Input-Output Change, (Cambridge University Press, London), 1970.

2. Boisvert, Richard N. and Nelson L. Bills. "A Non-Survey Technique for Regional I-O Models: Application to River Basin Plannning." Agriculture Experiment Station Report 76-19, August 1976.

3. Brucker, Sharon M. and Gerald L. Cole. "An InputOutput Study of Sussex County, Delaware," Delaware Agricultural Experiment Station Bulletin No. 428, July 1979.

4. Burford, Roger L. and Joseph L. Katz. "A Method for Estimation of Input-Output Type Output Multipliers When No I-O Model Exists," Journal of Regional Science, V, 21, No. 2, May 1981, pp. 151-161.

5. Cartwright, Joseph U., Richard M. Bumiller and Richard D. Gustily. RIMSII Regional Input-Output Modeling System, U.S. Department of Commerce, Bureau of Economic Analysis, U.S. Government Printing Office, Washington, D.C. 20402, April 1981.

6. Czamanski, S. and E. E. Malizia. "Applicability and Limitations in the Use of National Input-Output Tables for Regional Studies," Papers and Proceedings of the Regional Science Association, 23, 65-77, 1969.

7. Department of Applied Economics, University of Cambridge. "A Computable Model of Economic Growth, A Programme for Growth, Number 1" (Chapman and Hall, London) 1962.

8. Drake, R. L. "A Short-Cut to Estimates of Regional Input-Output Multipliers: Methodology and Evaluation." International Regional Science Review, Vol. 1, 117, Fall 1976.

9. Hewings, G. J. "Regional Input-Output Models Using National Data: The Structure of the West Midlands Economy," Annals of Regional Science, 3, 179-191, 1969.

10. —. "Input-Output Models: Aggregation for Regional Impact Analysis," Growth and Change 3: pp. 15-19.

11. Isard, Walter. "Regional Commodity Balances and Interregional Commodity Flows," The American Economic Review XLIII, pp. 167-180, May 1953.
12. Jensen, R. C. "Some Accounting Procedures and Their Effects on Input-Output Multipliers." The Annals of Regional Science, Vol. 12, 21-38, November 1978a.

13. Lecomber J. R. C. "A Critique of Methods of Adjusting, Updating and Projecting Matricies, Together with Some New Proposals." Paper presented to Conference on Input-Output and Throughput, University of East Anglia, September 13-16, 1971.

14. Leontief, W. W. "Quantitative Input-Output Relations in the Economic System of the United States." Review of Economics and Statistics, 18, 105-125, 1936.

15. Malizia, E. and D. L. Bond. "Empirical Tests of the RAS Technique of Interindustry Coefficient Adjustment." Journal of Regional Science, Vol. 14, 335-365, December 1974.

16. McMenamin, D. G. and J. E. Haring. "An Appraisal of Non-Survey Techniques for Estimating Regional Input-Output Models," Journal of Regional Science, 14:191-205, 1974.

17. Miernyk, W. H. "Comments of Recent Developments in Regional Input-Output Analysis." International Regional Science Review 1, 2: 47-55, 1976.

18. Moore and Peterson. "Regional Analysis: An Interindustry Model of Utah," Review of Economics and Statistics, 37:368-383, 1955.

19. Morrison, W. I. and P. Smith. Stimulating the Urban Economy. (Pion Limited: London) 1974.

20. Schaffer, W. A. "Estimating Regional Input-Output Coefficients," Review of Regional Studies, 2, 57-71, 1972.

21. Schaffer, W. A. and K. Chu. "Nonsurvey Techniques for Constructing Regional Interindustry Models," Papers, Regional Science Association, 23, 83-101, 1969.

22. Shen, T. Y. "An Input-Output Table with Regional Weights," Papers, Regional Science Association, 6, 113$119,1960$.

23. State of Delaware, Department of Labor, ES 202 Employment Data, 1972.

24. Stevens, B. H. and G. A. Trainer. "The Generation of Error in Regional Input-Output Impact Models," Working papers A1-76, Regional Science Institute, 1976.

25. Stevens, B. H., George I. Treyz and David J. Ehrlich. "On the Estimation of Regional Purchase Coefficients, Export Employment and Elasticities of Response for Regional Economic Models," discussion paper 114, Regional Science Institute, January 1980.

26. Stevens, B. H., D. J. Ehrlich, J. K. Kendahl and G. I. Treyz. "Basic Regional Input-Output for Transportation Impact Analysis. Handbook One of Regional Economic Analysis for Transportation Planning." Prepared under project 8-15A National Cooperative Highway Research Program. Regional Science Research Institute, Amherst, Massachusetts, March 1981.

27. Stone, R. "Demographic Input-Output: An Extension of Social Accounting," in Contributions to Input-Output Analysis, Eds. A. P. Carter, A. Brody (North Holland, Amsterdam), Chapter 15, 1970.

28. Su, T. T. "A Note on Regional Input-Output Models," Southern Economic Journal, 37, 325, 327, 1970.

29. "A Study of the 1972 U.S. Input-Output Tables," a paper presented at the meeting of the American Statistical Association, Houston, Texas, August 11-14, 1980.

30. U.S. Bureau of the Census. Census of Agriculture, 1969, Delaware Individual County Reports, Washington, D.C.: Government Printing Office, 1972.

31. Census of Business, Wholesale and Retail Trade, 1972. Washington, D.C.: Government Printing Office, 1973. 
32. Census of Business, Selected Services, 1972. Washington, D.C.: Government Printing Office, 1973.

33. Census of Governments, 1972. Washington, D.C.: Government Printing Office, 1973.

34. Census of Manufacturers, 1972. Washington, D.C.: Government Printing Office, 1973.

35 . County Business Patterns, 1972. Wash- ington, D.C.: Government Printing Office, 1973.

36. U.S. Department of Commerce, Bureau of Economic Analysis. Detailed Input-Output Structure of the U.S. Economy: 1972, Vol. 1, Washington, D.C., 1979.

37. "Input-Output Structure of the U.S. Economy: 1972." Survey of Current Business, Washington, D.C., February 1974 . 
APPENDIX A TABLE 1

Sector Composition Used in the Comparison of the Survey Table to Tables Estimated from Disaggregated U.S. I-O Tables (496 Sectors).

\begin{tabular}{|c|c|c|c|}
\hline Sectors & $\begin{array}{l}\text { Sussex County } \\
\text { Survey Sectors }\end{array}$ & $\begin{array}{l}\text { U.S. I-O } \\
\text { Sectors } \\
(1-496)^{b}\end{array}$ & $\begin{array}{l}\text { SIC Codes } \\
\text { (included) }\end{array}$ \\
\hline 1 Field Crops & 1 & $5-9,13-17$ & 011-0139 \\
\hline 2 Frt. Veg. & 2 & $10-12$ & 016-0189 \\
\hline 3 Livestock & 3 & $1,3 \& 4$ & $021-0241,027-0291$ \\
\hline 4 Broilers & 4 & 2 & 025-0259 \\
\hline 5 Vet. & 6 & 477 & 0741,0742 \\
\hline 6 Ag Supply & 8 & $19,102,103,457$ & $071-0729,075-0783$ \\
\hline 7 P. Proc. & 9 & $83-91$ & $201-2026$ \\
\hline 8 V. Proc. & 10 & $92-101,104-126$ & 203-2099 \\
\hline 9 Fishfsim & 11 & $18,20-26$ & 08-1499 \\
\hline 10 Cons. New & 12 & 27-59 & $15,16,17$ \\
\hline 11 Cons. Mnt. & 13 & $60-76$ & $15,16,17$ \\
\hline 12 Apparel & 14 & $145-151$ & 23 \\
\hline 13 Oth. Man. & 15 & $127-144,152-443$ & $21,22,24-39$ \\
\hline 14 Trans. & 16 & $444-450$ & $40,41,42,44-47$ \\
\hline 15 Commun. & 17 & $451-452$ & 48 \\
\hline 16 Utility & 18 & $453-455$ & 49 \\
\hline 17 Whsl. Td. & 19 & 456 & 50,51 \\
\hline 18 Restaur. & 28 & 471 & 5812,5813 \\
\hline 19 Ret. Trade & $7,20-27,29-31$ & 457 & $52-59$ \\
\hline 20 Finance & 32 & $458-460,486$ & $60,61,62$ \\
\hline 21 Insurance & 33 & 461,462 & 63,64 \\
\hline 22 Real Estate & 34 & 463,464 & $65,66,67$ \\
\hline 23 Lodging & 35,36 & 465 & 701-704 \\
\hline 24 Pers. Ser. & 37 & 466,467 & 72 \\
\hline 25 Repair & 38 & 472 & 76,76 \\
\hline 26 Amusement & 39 & 473,474 & 78,79 \\
\hline 27 Prof. Ser. & 41 & 470 & 81,89 \\
\hline 28 Other Ser. & 42 & $468,469,475-483$ & $73,80,83,84,86$ \\
\hline 29 Education & 40 & 478 & 82 \\
\hline Households & Households & Consumption (column) ${ }^{c}$ & - \\
\hline \multirow[t]{2}{*}{ Imports } & Imports & Sector No. 491 and estimates & \\
\hline & & of competing and noncompeting & - \\
\hline
\end{tabular}

aBrucker and Cole, op. cit. p. 18.

"Detailed Input-Output Structure of the U.S. Economy: 1972, "U.S. Department of Commerce, Bureau of Economic Analysis, 1979.

"Value added row elements were modified on basis of ratio of wages, salary and proprietary payment components of total value added from Scientific American's Wall Chart, "Input-Output Structure of the United States Economy," 1980. 
APPENDIX A TABLE 2

Sector Composition Used in the Comparison of the Survey Table to Tables Estimated from Aggregated U.S. I-O

Tables (77 Sectors).

\begin{tabular}{|c|c|c|}
\hline Sector & $\begin{array}{l}\text { Sussex County } \\
\text { Survey Sectors }^{\mathrm{a}}\end{array}$ & $\begin{array}{c}\text { U.S. I-O } \\
\text { Sectors }(1-77)^{b}\end{array}$ \\
\hline 1 Field Crops & 1,2 & 2 \\
\hline 2 Livestock & 3,4 & 1 \\
\hline 3 Ag Supply & 8 & 4 \\
\hline 4 Food Proc. & 9,10 & 14 \\
\hline 5 Fishfsim. & 11 & $5-10$ \\
\hline 6 Cons. New & 12 & 11 \\
\hline 7 Cons. Mtn. & 13 & 12 \\
\hline 8 Apparel & 14 & 18 \\
\hline 9 Other Man. & 15 & $13,15,16,17,19-64$ \\
\hline 10 Trans. & 16 & 65 \\
\hline 11 Commun. & 17 & 66,67 \\
\hline 12 Utility & 18 & 68 \\
\hline 13 Trade & $19,20-27,29-31$ & 69 \\
\hline 14 Restaur. & 18 & 74 \\
\hline 15 Finance & 32,33 & 70 \\
\hline 16 Real Estate & 34 & 71 \\
\hline 17 Lodging & $35,36,37$ & 72 \\
\hline 18 Repair & 38 & 75 \\
\hline 19 Amusement & 39 & 76 \\
\hline 20 Prof. Ser. & 41 & 73 \\
\hline 21 Other Ser. & 42 & 77 \\
\hline
\end{tabular}

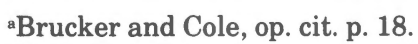

b"The Input-Output Structure of the U.S. Economy, 1972."

Philip M. Ritz, Survey of Current Business, February 1979. 
APPENDIX A TABLE 3

Estimated Imports for Sussex County.

\begin{tabular}{|c|c|c|c|c|c|c|c|}
\hline \multirow[b]{2}{*}{ Sector } & \multicolumn{4}{|c|}{ Total Imports $(\$ 1,000$ 's) } & \multicolumn{3}{|c|}{ Proportional Differences } \\
\hline & Survey & LQE & LQP & POOL & LQE & LQP & POOL $^{a}$ \\
\hline 1 F. Crops & 2261.9 & 3299.8 & 2083.3 & 5852.1 & .4589 & .0790 & .5006 \\
\hline 2 Frt Veg. & 1783.3 & 1738.8 & 1268.4 & 3728.5 & .0250 & .2887 & .1624 \\
\hline 3 Livestock & 828.1 & 1791.4 & 1578.6 & 2192.0 & 1.1633 & .9063 & 1.0364 \\
\hline 4 Broilers & 54417.9 & 11664.3 & 9372.7 & 51596.1 & .7857 & .8278 & .1029 \\
\hline 5 Vet. & 1512.5 & 703.3 & 525.3 & 1527.0 & .5350 & .6527 & .5357 \\
\hline $6 \mathrm{Ag}$ Suppl & 326.2 & 1788.2 & 1534.2 & 2826.4 & 4.4819 & 3.7032 & 6.1076 \\
\hline 7 P. Proc. & 25058.3 & 5810.5 & 4504.4 & 7969.0 & .7681 & .8202 & .7808 \\
\hline 8 V. Proc. & 24934.0 & 19418.6 & 16981.5 & 21373.3 & .2212 & .3189 & .2478 \\
\hline 9 Fishfsim. & 53.6 & 226.5 & 196.7 & 391.2 & 3.2267 & 2.6691 & 3.3594 \\
\hline 10 Cons. New & 27452.6 & 28216.3 & 26716.0 & 33187.9 & .0278 & .0268 & .0241 \\
\hline 11 Cons. Mnt. & 8690.5 & 5239.0 & 4831.5 & 8513.7 & .3972 & .4440 & .4070 \\
\hline 12 Apparel & 20939.1 & 14896.8 & 13959.4 & 18146.3 & .2886 & .3333 & .2940 \\
\hline 13 Oth Man & 135279.3 & 109193.3 & 96838.2 & 153596.1 & .1928 & .2842 & .2089 \\
\hline 14 Trans. & 4839.4 & 2048.0 & 3028.9 & 6128.3 & .5768 & .3741 & .3281 \\
\hline 15 Commun. & 1486.9 & 1747.5 & 1711.9 & 3189.0 & .1753 & .1513 & .2458 \\
\hline 16 Utility & 2605.78 & 3546.2 & 2384.5 & 4871.7 & .3609 & .0849 & .0166 \\
\hline 17 Whlsl. Td. & 1980.9 & 1096.3 & 851.7 & 2472.0 & .4466 & .5701 & .4701 \\
\hline 18 Restaur. & 9572.6 & 7922.8 & 6679.8 & 9878.9 & .1723 & .3022 & .1856 \\
\hline 19 Ret Trade & 15423.9 & 7816.4 & 4241.6 & 19430.2 & .4932 & .7250 & .5198 \\
\hline 20 Finance & 285 & 2385.5 & 1996.6 & 4778.1 & 7.3703 & 6.0057 & 7.1848 \\
\hline 21 Insur. & 12732 & 4451.2 & 3886.4 & 7708.8 & .6504 & .6948 & .6558 \\
\hline 22 Real Est. & 1701 & 1511.3 & 557.1 & 4458.1 & .1115 & .6725 & .1252 \\
\hline 23 Lodging & 771.4 & 1485.6 & 719.4 & 2375.1 & .9259 & .0674 & .8652 \\
\hline 24 Pers. Ser. & 896.9 & 1081.9 & 770.5 & 1842.1 & .2063 & .1410 & .1969 \\
\hline 25 Repair & 1467.6 & 1240.5 & 1116.5 & 1597.6 & .1548 & .2392 & .1576 \\
\hline 26 Amuse. & 1008 & 788.9 & 649.0 & 1393.1 & .2173 & .3562 & .1549 \\
\hline 27 Profess. & 1604.2 & 986.0 & 794.5 & 2675.2 & .3853 & .5047 & .3904 \\
\hline 28 Oth. Ser. & 1963.9 & 1193.7 & 863.0 & 2428.6 & .3922 & .5606 & .3978 \\
\hline 29 Educ. & 1983.4 & 3669.4 & 1852.4 & 7165.5 & .8501 & .0661 & .8120 \\
\hline Sum & 363860.1 & 246958.2 & 212493.9 & 393291.7 & 26.0613 & 22.8700 & 26.4742 \\
\hline Mean & & & & & .8987 & .7886 & .9129 \\
\hline
\end{tabular}

${ }^{a}$ Not adjusted for non-resident employees. 
APPENDIX A TABLE 4

Sectors With Non-Reject Criterion Levels ${ }^{\mathrm{a}}$

\begin{tabular}{|c|c|c|c|c|}
\hline Sector & LQE & LQP & POOL & $\begin{array}{l}\text { Method } \\
\text { With } \\
\text { Lowest } \\
\mathrm{X}^{2} \text { for } \\
\text { This } \\
\text { Sector }\end{array}$ \\
\hline 1 F. Crops & & & & LQP \\
\hline 2 Frt. Veg & & & & LQP \\
\hline 3 Livestock & $\mathrm{X}$ & $\mathbf{X}$ & & LQP \\
\hline 4 Broilers & & & $\mathbf{X}$ & POOL \\
\hline 5 Vet. & $\mathrm{X}$ & $\mathbf{X}$ & $\mathbf{X}$ & POOL \\
\hline 6 Ag Supply & & $\mathrm{X}$ & $\mathrm{X}$ & POQL \\
\hline 7 P. Proc. & & & $\mathrm{X}$ & POOL \\
\hline 8 V. Proc. & $\mathrm{X}$ & $\mathrm{X}$ & $\mathrm{X}$ & LQP \\
\hline 9 Fishfsim. & $\mathbf{X}$ & $\mathbf{X}$ & $\mathrm{X}$ & POOL \\
\hline 19 Cons. New & & & & LQE \\
\hline 11 Cons. Mnt. & & $\mathbf{X}$ & $\mathbf{X}$ & POOL \\
\hline 12 Apparel & $\mathrm{X}$ & $\mathbf{X}$ & $\mathbf{X}$ & LQP \\
\hline 13 Oth. Man. & $\mathrm{X}$ & $\mathrm{X}$ & $\mathbf{X}$ & LQP \\
\hline 14 Trans. & $\mathrm{X}$ & $\mathbf{X}$ & $\mathbf{X}$ & POOL \\
\hline 15 Commun. & $\mathrm{X}$ & $\mathrm{X}$ & $\mathbf{X}$ & POOL \\
\hline 16 Utility & $\mathbf{X}$ & $\mathbf{X}$ & $\mathbf{X}$ & LQP \\
\hline 17 Whlsl. Td. & & & & POOL \\
\hline 18 Restaurant & & & & POOL \\
\hline 19 Ret. Trade & & & & POOL \\
\hline 20 Finance & & $\mathrm{X}$ & $\mathbf{X}$ & POOL \\
\hline 21 Insurance & $\mathbf{X}$ & $\mathrm{X}$ & $\mathrm{X}$ & LQP \\
\hline 22 Real Estate & & & & POOL \\
\hline 23 Lodging & & & & POOL \\
\hline 24 Pers. Ser. & & & $\mathrm{X}$ & POOL \\
\hline 25 Repair & $\mathrm{X}$ & $\mathrm{X}$ & $\mathbf{X}$ & POOL \\
\hline 26 Amusement & $\mathrm{X}$ & $\mathrm{X}$ & $\mathrm{X}$ & POOL \\
\hline 27 Profess. & $\mathrm{X}$ & $\mathrm{X}$ & $\mathbf{X}$ & POOL \\
\hline 28 Other Ser. & & & & LQE \\
\hline 29 Education & & & & POOL \\
\hline Significant Sectors & 13 & 16 & 18 & \\
\hline
\end{tabular}

${ }^{a}$ Calculated using columns of direct requirements tables without households. Criterion value for .05 level of significance is 41.44 . 